\title{
AVALIAÇÃO DE PROGRAMAS DE FORMAÇÃO PROFISSIONAL EM SAÚDE: CONSTRUÇÃO E VALIDAÇÃO DE INDICADORES
}

\author{
EVALUATION OF PROFESSIONAL TRAINING PROGRAMS IN HEALTH: INDICATOR CONSTRUCTION AND \\ VALIDATION
}

\section{EVALUACIÓN DE PROGRAMAS DE FORMACIÓN PROFESIONAL EN SALUD: CONSTRUCCIÓN Y VALIDACIÓN DE INDICADORES}

\author{
Tereza Cristina Alves Bezerra ${ }^{1}$ \\ Maria Leopoldina Padilha Falcão ${ }^{2}$ \\ Paulo Sávio Angeiras de Goes ${ }^{3}$ \\ Eronildo Felisberto ${ }^{4}$
}

Resumo Este artigo teve como objetivo elaborar um instrumento qualificador visando contribuir para o monitoramento e a avaliação do Programa de Residência Multiprofissional em Saúde da Família. Foi um estudo avaliativo exploratório desenvolvido em duas fases: a primeira, constituída pela construção e validação de face do modelo lógico e da matriz de indicadores, por meio de análise documental e da técnica de consenso grupo nominal. Essa primeira fase, por sua vez, aconteceu em dois momentos, pré e pós-reunião de consenso, nos quais se procurou validar um modelo lógico e uma matriz de indicadores que refletissem os principais elementos avaliativos do programa. A segunda fase compreendeu a construção do instrumento avaliativo. A partir do grupo de consenso, foram validados um modelo lógico e a matriz de indicadores, o que resultou em 32 indicadores, utilizados para a construção do instrumento avaliativo que se formatou por meio de questionário estruturado. Este questionário foi composto por 35 perguntas avaliativas distribuídas em 19 questões na dimensão gestão do programa; cinco na dimensão estrutura organizacional e 11 na dimensão processo pedagógico. O instrumento elaborado, baseado em protocolo aceito universalmente para esse fim, precisará ser aplicado em pesquisas futuras para completar seu processo de validação.

Palavras-chave avaliação de programas; gestão pública; Estratégia Saúde da Família; formação profissional em saúde.
Abstract This paper aimed to develop a qualifying instrument to contribute to the monitoring and evaluation of the Multidisciplinary Residency Program in Family Health. It was an exploratory evaluation study carried out in two phases: the first comprising the face construction and validation of the logic model and of the indicator matrix, through document analysis and a nominal group consensus technique. The first phase, in turn, took place in two stages, before and after the consensus meeting, in which the goal was to validate a logical model and an indicators matrix that would reflect the main evaluative elements of the program. The second phase included the construction of the evaluation instrument. A logical model and the indicator matrix were validated based on the work done by the consensus groups, the outcome of which was 32 indicators used to build the evaluation instrument that was formatted through a structured questionnaire. This questionnaire consisted of 35 evaluative questions divided into 19 questions in the program management dimension; five in the organizational structure dimension, and 11 in the educational process dimension. The instrument that was prepared, based on a universally accepted protocol for this purpose, will need to be applied in future surveys for its validation process to be completed.

Keywords program evaluation; public administration; Family Health Strategy; professional training in health. 


\section{Introdução}

A formação de recursos humanos para atuação no Sistema Único de Saúde (SUS) tem sido um dos principais obstáculos à sua consolidação. Estes se tornaram mais evidentes a partir da implantação do novo modelo de atenção à saúde com foco na atenção básica como instância ordenadora do sistema, com base na Estratégia Saúde da Família (ESF). Esta estratégia surgiu do pressuposto da potencialidade em reorientar o modelo assistencial, com base no trabalho multiprofissional para uma abordagem integral à família e não apenas ao indivíduo (Brasil, 2002).

A maioria das instituições formadoras para a área de saúde no Brasil ainda privilegia o modelo de saúde disciplinar, com prioridade para a formação especializada, organizado sob a égide 'flexneriana' (Pagliosa e Da Ros, 2008) e, consequentemente, de forma fragmentada e compartimentalizada - o que impede o aluno de ter uma visão geral do paciente e do contexto onde vive.

Ao longo das últimas duas décadas, várias estratégias de aproximação entre as políticas assistenciais e de formação profissional em saúde vêm sendo desenvolvidas visando à adequação do perfil profissional à centralidade da atenção básica para a reorientação do modelo de atenção. Entre os exemplos dos dispositivos que foram colocados em prática, destacam-se: Curso Introdutório em Saúde da Família; Curso de Especialização em Saúde da Família; Programa Nacional de Reorientação da Formação Profissional em Saúde (Pró-Saúde); Programa de Educação para o Trabalho em Saúde (PET-Saúde) e os Programas de Residência Multiprofissional em Saúde (PRMS), entre estes o Programa de Residência Multiprofissional em Saúde da Família (PRMSF).

Nesse contexto, o PRMSF é considerado uma das principais alternativas de formação técnica, por apresentar uma perspectiva teórica e pedagógica convergente com os princípios e diretrizes do SUS, promovendo exitosa aproximação entre o trabalho e a formação. Possibilita ainda mudanças do modelo técnico-assistencial, em razão do caráter multidisciplinar e da disponibilidade de espaços estratégicos para as mudanças nos cenários de formação e das práticas de saúde, fortalecendo a relação ensino-serviço e contribuindo com práticas mais aproximadas às concepções de integralidade e de humanização da atenção.

O financiamento desse programa teve início em 2002, com recursos oriundos do Projeto Reforço à Reorganização do Sistema Único de Saúde (ReforSUS). Seu reconhecimento como ensino de pós-graduação lato sensu foi em 2008 (Brasil, 2006; Nascimento e Oliveira, 2010).

Mais recentemente, o financiamento dos cursos vem se dando com base em programas específicos, seja por fomento da gestão federal, seja por ini- 
ciativas de governos estaduais ou municipais. O PRMSF tem, portanto, desafios primários a serem superados, entre os quais se destacam: o credenciamento definitivo, sua inserção como dispositivo da política de formação de recursos humanos para o SUS e a definição de fontes estáveis de financiamento.

Por sua vez, a qualidade da formação oferecida tem íntima relação com a definição e a clareza dos objetivos de aprendizagem, com o acompanhamento sistemático do cumprimento das metas estabelecidas para o seu alcance, bem como a capacidade de adaptação às necessidades decorrentes da evolução tecnológica setorial e das necessidades do SUS em atender às demandas sociais. Nesse sentido, o monitoramento e a avaliação apresentam-se como estratégias fundamentais visando à superação de algumas das dificuldades referidas aqui. Para isso, faz-se necessário desenvolver instrumentos que possibilitem a produção de informações qualificadas para o aprimoramento do PRMSF. Essas estratégias complementares permitem contribuir para maior responsabilização dos gestores, coordenadores de curso e docentes, à luz de maior transparência e qualidade das atividades executadas (Bezerra et al., 2012; Costa et al., 2013).

Este artigo buscou apresentar o processo de construção e o instrumento desenvolvido com base nos pressupostos teóricos que nortearam a criação do PRMSF e em critérios normativos essenciais à garantia da qualidade do processo ensino-aprendizagem, para a avaliação dos Programas de Residência Multiprofissional em Saúde da Família (Bezerra et al., 2012; Felisberto et al., 2012; Tamaki et al., 2012).

\section{Aspectos metodológicos}

O estudo 5 apresentado neste artigo foi do tipo avaliativo e exploratório, visando ao desenvolvimento de um instrumento para avaliação dos Programas de Residência Multiprofissional em Saúde com foco na Estratégia Saúde da Família. Desenvolveu-se em duas fases. A fase I foi constituída pela construção e validação do modelo lógico e da matriz de indicadores, e a fase II, pela elaboração do instrumento de avaliação propriamente dito (Soares et al., 2012).

Para a fase I, considerou-se a importância do modelo lógico como uma representação esquemática dos componentes e da forma de operacionalização do programa. Este foi elaborado visando a uma compreensão melhor do problema, do contexto que o envolve e dos componentes essenciais do programa (Hartz, 1999; Medina et al., 2005; Alves et al., 2010). Para a construção do modelo lógico (Quadro 1) foi realizada análise documental, tendo sido selecionados e analisados documentos e recomendações oficiais, referentes à 
implantação e ao financiamento do PRMSF (Brasil, 2001; 2005a; 2005b; 2006; 2007; 2008a; 2008b; 2009; 2010).

Da análise dos documentos, foram extraídas informações referentes a problemas, possíveis causas e consequências deles, objetivo esperado do PRMSF, público-alvo, recursos, operações, ações, produtos, resultados e fatores relevantes do contexto. Todas essas informações foram agregadas em uma planilha de pré-montagem do modelo lógico (McLaughlin e Jordan, 1999; Alves et al., 2010). Em seguida, construiu-se a matriz de indicadores em três dimensões: gestão do programa, estrutura organizacional; e processo pedagógico.

Quadro 1

\begin{tabular}{|c|c|c|c|c|}
\hline Dimensão & & Atividades & Produtos & Resultado final \\
\hline \multirow{3}{*}{ 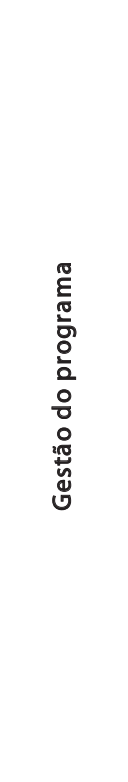 } & \multicolumn{2}{|c|}{$\begin{array}{l}\text { Revisão dos documentos normativos do PRMS em nível federal (MS/MEC); } \\
\text { Reunião/discussão do corpo docente do PRMS e instituições parceiras; } \\
\text { Concessão de anuência pelos municípios parceiros do PRMS; } \\
\text { Vinculação do PRMS a uma IES. }\end{array}$} & $\begin{array}{l}\text { Projeto político } \\
\text { pedagógico construído } \\
\text { e aprovado. }\end{array}$ & \multirow{3}{*}{ 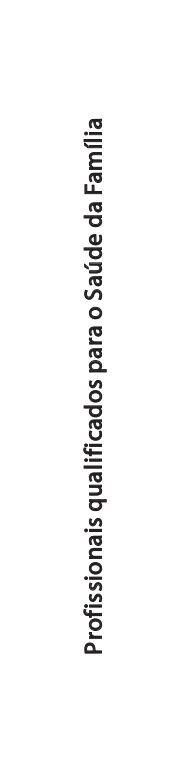 } \\
\hline & \multicolumn{2}{|c|}{$\begin{array}{l}\text { Seleção dos candidatos ao PRMS; } \\
\text { Reprodução de material didático; } \\
\text { Divulgação sistemática de notas; } \\
\text { Emissão de frequências, certificados e declarações; } \\
\text { Utilização do SIG-Residência para acompanhamento do PRMS. }\end{array}$} & $\begin{array}{l}\text { Escolaridade acadêmica } \\
\text { implantada. }\end{array}$ & \\
\hline & \multicolumn{2}{|c|}{$\begin{array}{l}\text { Identificação e contratação do supervisor do PRMS; } \\
\text { Elaboração do regimento interno da Residência Multiprofissional em Saúde; } \\
\text { Implantação e participação na Coremu; } \\
\text { Identificação dos tutores/preceptores e suas respectivas responsabilidades; } \\
\text { Definição do número de bolsas/categorias para alunos do programa; } \\
\text { Monitoramento de pagamentos de bolsas dos residentes; } \\
\text { Acompanhamento dos egressos do PRMS; } \\
\text { Apresentação de relatório final das atividades do biênio do PRMS. }\end{array}$} & $\begin{array}{l}\text { Secretaria acadêmica } \\
\text { implantada. }\end{array}$ & \\
\hline 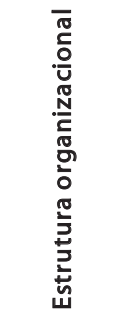 & $\frac{\frac{8}{4}}{\frac{\pi}{4}}$ & $\begin{array}{l}\text { Biblioteca com acervo apropriado; } \\
\text { Salas de aula; } \\
\text { Auditórios; } \\
\text { Ambulatórios clínicos por especialidades; } \\
\text { Laboratório de informática; } \\
\text { Recursos audiovisuais; } \\
\text { Monitoramento dos equipamentos e infraestrutura das unidades } \\
\text { básicas de saúde de ensino. }\end{array}$ & $\begin{array}{l}\text { Provimento de } \\
\text { infraestrutura e apoio } \\
\text { logístico-físico. }\end{array}$ & 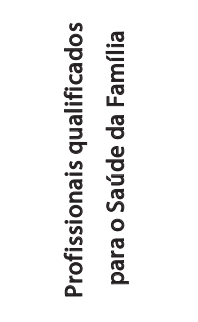 \\
\hline
\end{tabular}


Continuação - Quadro 1

\begin{tabular}{|c|c|c|c|c|}
\hline Dimensão & & Atividades & Produtos & Resultado final \\
\hline \multirow{2}{*}{ 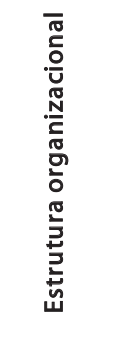 } & 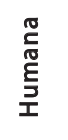 & $\begin{array}{l}\text { Quantitativo adequado de apoio técnico; } \\
\text { Número de preceptores e tutores com qualificação adequada; } \\
\text { Supervisores do programa. }\end{array}$ & $\begin{array}{l}\text { Preceptores } \\
\text { qualificados atuando } \\
\text { sob supervisão. }\end{array}$ & \multirow{2}{*}{ 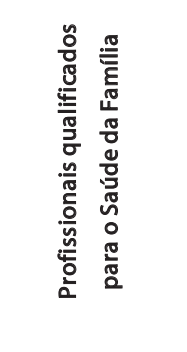 } \\
\hline & : & $\begin{array}{l}\text { Identificação da fonte pagadora do PRMS; } \\
\text { Pagamento das bolsas de residentes; } \\
\text { Definição do financiamento de bolsas para pagamento de } \\
\text { preceptores/tutores. }\end{array}$ & $\begin{array}{l}\text { Sustentabilidade } \\
\text { financeira garantida. }\end{array}$ & \\
\hline \multirow{3}{*}{ 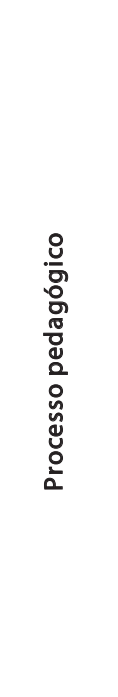 } & 焉 & $\begin{array}{l}\text { Formação e capacitação de tutores/preceptores (educação } \\
\text { permanente); } \\
\text { Coerência pedagógica entre o Projeto do Programa de Residência e } \\
\text { as disciplinas oferecidas; } \\
\text { Construção de competências multi e específicas para docentes e } \\
\text { residentes; } \\
\text { Construção de habilidades multi e específicas para docentes e } \\
\text { residentes. }\end{array}$ & $\begin{array}{l}\text { Estabelecimento do } \\
\text { marco teórico voltado } \\
\text { para a Estratégia Saúde } \\
\text { da Família. }\end{array}$ & \multirow{3}{*}{ 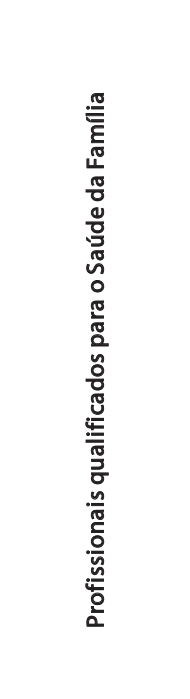 } \\
\hline & 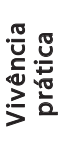 & $\begin{array}{l}\text { Articulação entre os serviços (cenário de práticas) e conteúdo } \\
\text { teórico; } \\
\text { Diversificação das atividades didáticas. }\end{array}$ & $\begin{array}{l}\text { Competência e } \\
\text { habilidades consolidadas } \\
\text { para atuação no Saúde } \\
\text { da Família }\end{array}$ & \\
\hline & 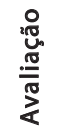 & $\begin{array}{l}\text { Modelos de avaliação adotados: } \\
\text { Formativo; } \\
\text { Somativo. }\end{array}$ & $\begin{array}{l}\text { Modelo de avaliação } \\
\text { implantado. }\end{array}$ & \\
\hline
\end{tabular}

Fonte: Elaborado pelos autores.

Nota:PRMS - Programa de Residência Multiprofissional em Saúde; IES - instituição de ensino superior; MS/MEC - Ministério da Saúde e Ministério da Educação; SIG-Residência - Sistema de Informação Gerencial dos Programas de Residência-MEC; Coremu - Comissão de Residência Multiprofissional.

O processo de validação do modelo lógico e da matriz de indicadores foi realizado com base na técnica de consenso grupo nominal (Jones e Hunter, 1995; Uchoa et al., 2008). A fase I do estudo foi realizada em dois momentos e permitiu ampla participação e interação entre os integrantes, contribuindo não só para a troca de informações como também para o amadurecimento de opiniões fundamentadas na crítica e na sistematização das ideias, de modo a facilitar a tomada de decisão com base no consenso grupal (Reis, 2010).

O primeiro momento consistiu no envio, via digital, de uma versão inicial do modelo lógico e da matriz de indicadores aos experts, para análise e 
julgamento inicial. O segundo momento aconteceu em reunião presencial com dez experts, convidados em razão de seu envolvimento com o PRMSF ou outras estratégias formativas do SUS. O grupo foi composto por um gestor municipal, um coordenador acadêmico, dois preceptores municipais, um gestor estadual, um aluno, um egresso e três tutores de Residência Multiprofissonal em Saúde. Caracterizou-se o grupo por sua constituição multiprofissional (médico, fonoaudiólogo, fisioterapeuta, assistente social, enfermeira, psicólogo e cirurgiã-dentista).

Na reunião presencial, após a apresentação pelo pesquisador do modelo lógico e do consolidado da votação inicial da matriz de indicadores, a sequência do processo de tomada de decisão foi a seguinte: realizou-se uma rodada de discussão sobre as respostas dos participantes, indicador por indicador, na qual cada expert verbalizou sua opinião ao grupo, a fim de que fossem clarificadas e avaliadas; e cada integrante do grupo, silenciosamente e de forma independente, revisou a sua avaliação inicial e votou presencialmente acerca das suas ideias sobre o modelo lógico e a matriz de indicadores propostos. Avaliou em termos qualitativos de acordo com a pertinência e a importância de cada indicador - classificando-o como indispensável, necessário ou dispensável. O julgamento foi qualitativo e dele dependeu a manutenção do indicador na matriz - devendo ser retirados todos os considerados dispensáveis na avaliação da pós-conferência. De modo a reforçar o julgamento qualitativo, ou seja, após a classificação do indicador, o julgador deveria atribuir-lhe um valor que variava de 0 a 6 , sendo mantidos na matriz aqueles indicadores que obtivessem na sua classificação um percentual igual ou superior a $50 \%$ na nota máxima atribuída (6) entre os membros do grupo na pós-reunião de consenso.

A formulação do instrumento avaliador - fase II - se deu após o processo de validação do modelo lógico e da matriz de indicadores. Constituiu-se em um questionário estruturado refletindo os indicadores da matriz consensuada.

O projeto foi submetido ao Comitê de Ética em Pesquisa do Instituto de Medicina Integral Professor Fernando Figueira (Imip) e aprovado mediante o parecer n. 2.155/11. Todos os participantes do estudo assinaram termo de consentimento livre e esclarecido.

\section{Resultados}

A análise da matriz de indicadores, realizada pelos participantes do grupo de consenso na etapa anterior à presencial, revelou que a grande maioria dos indicadores era compatível com o modelo lógico proposto e atendia aos objetivos da avaliação, uma vez que não foram sugeridas grandes alterações na matriz. Salienta-se que nenhum indicador das três dimensões foi considerado dispensável na avaliação qualitativa da pós-conferência. 
Quadro 2

\section{Distribuição de frequência dos aspectos quantitativos e qualitativos do grupo de consenso nominal}

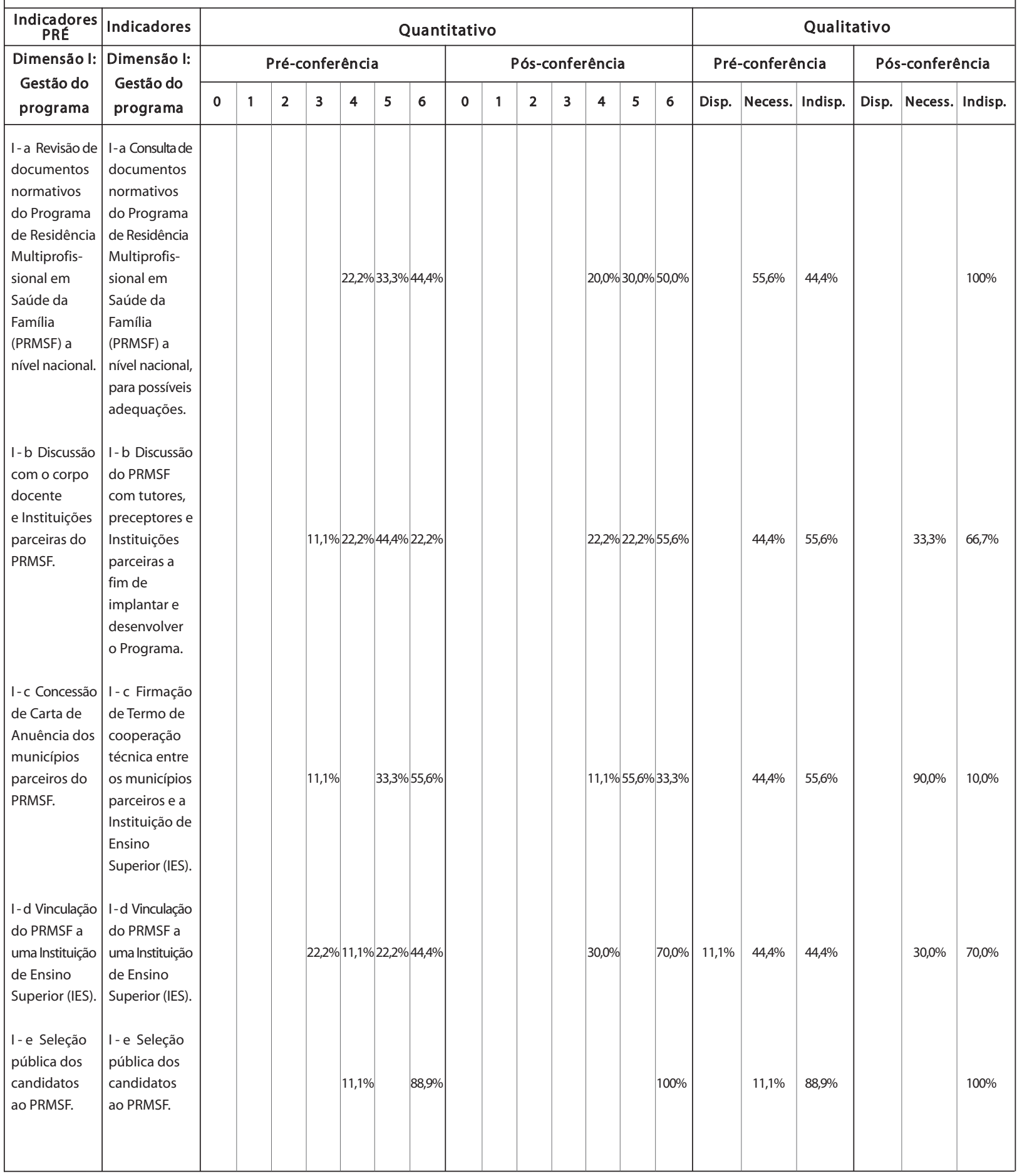


Continuação - Quadro 2

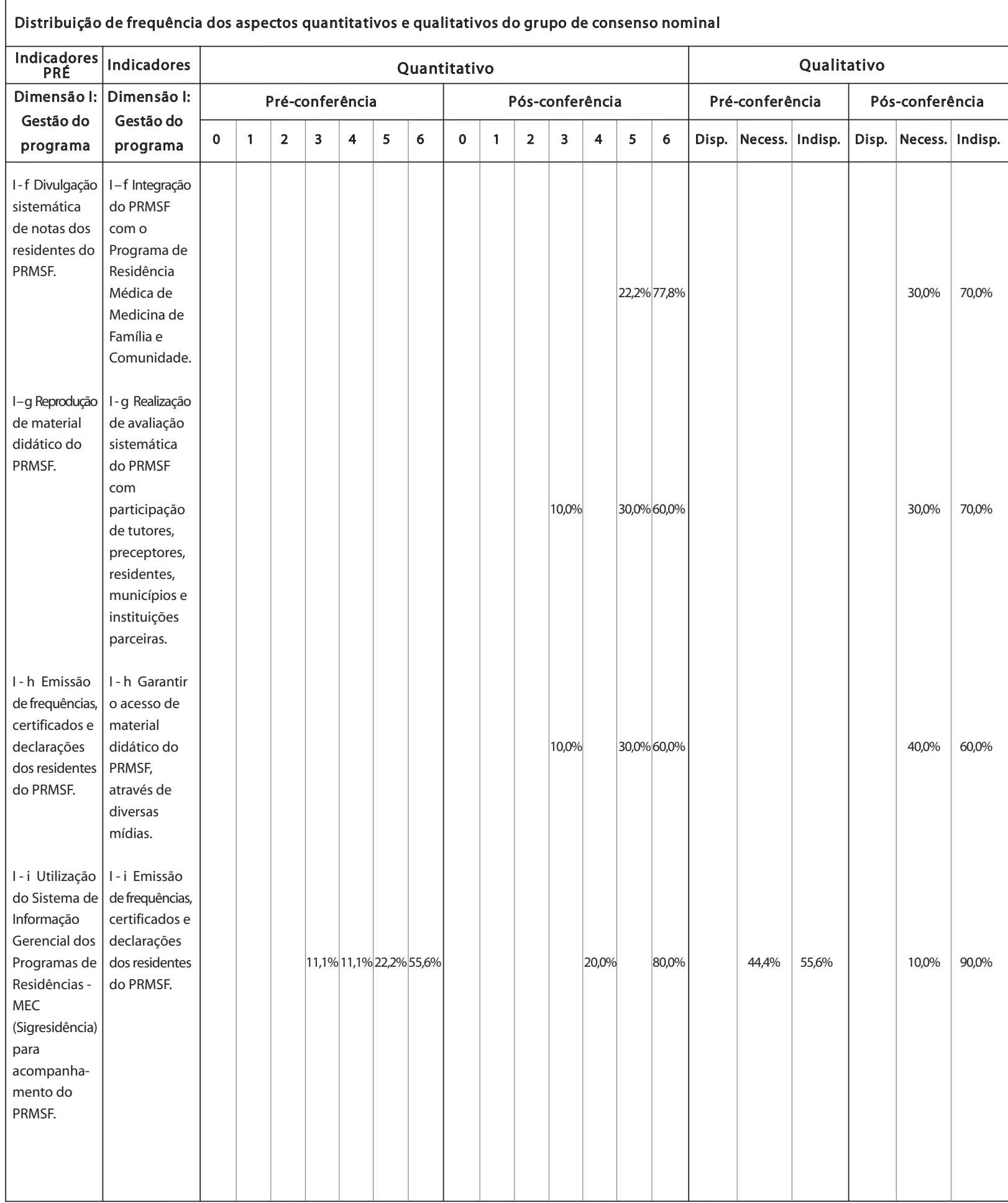


Continuação - Quadro 2

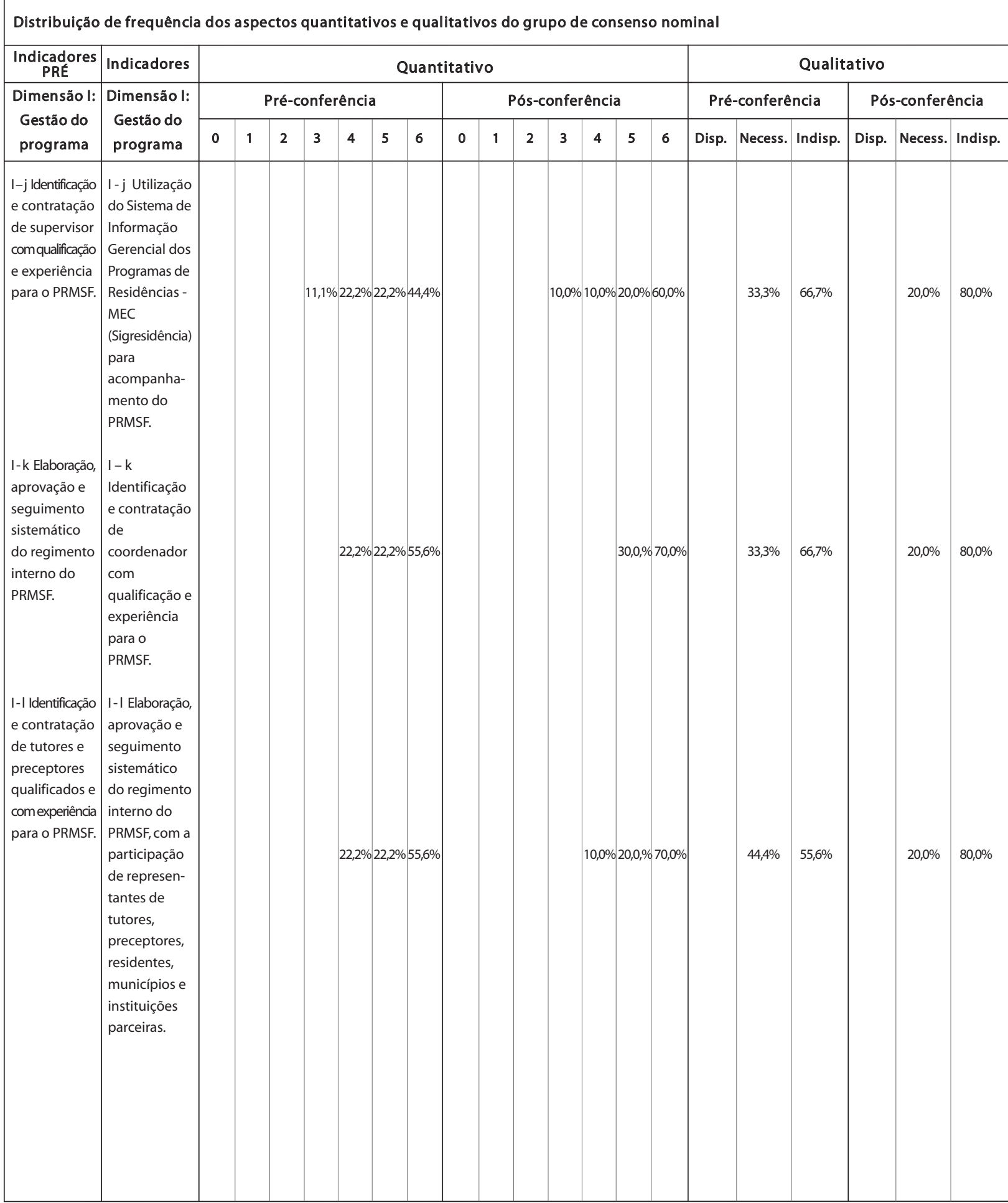


Continuação - Quadro 2

\section{Distribuição de frequência dos aspectos quantitativos e qualitativos do grupo de consenso nominal}

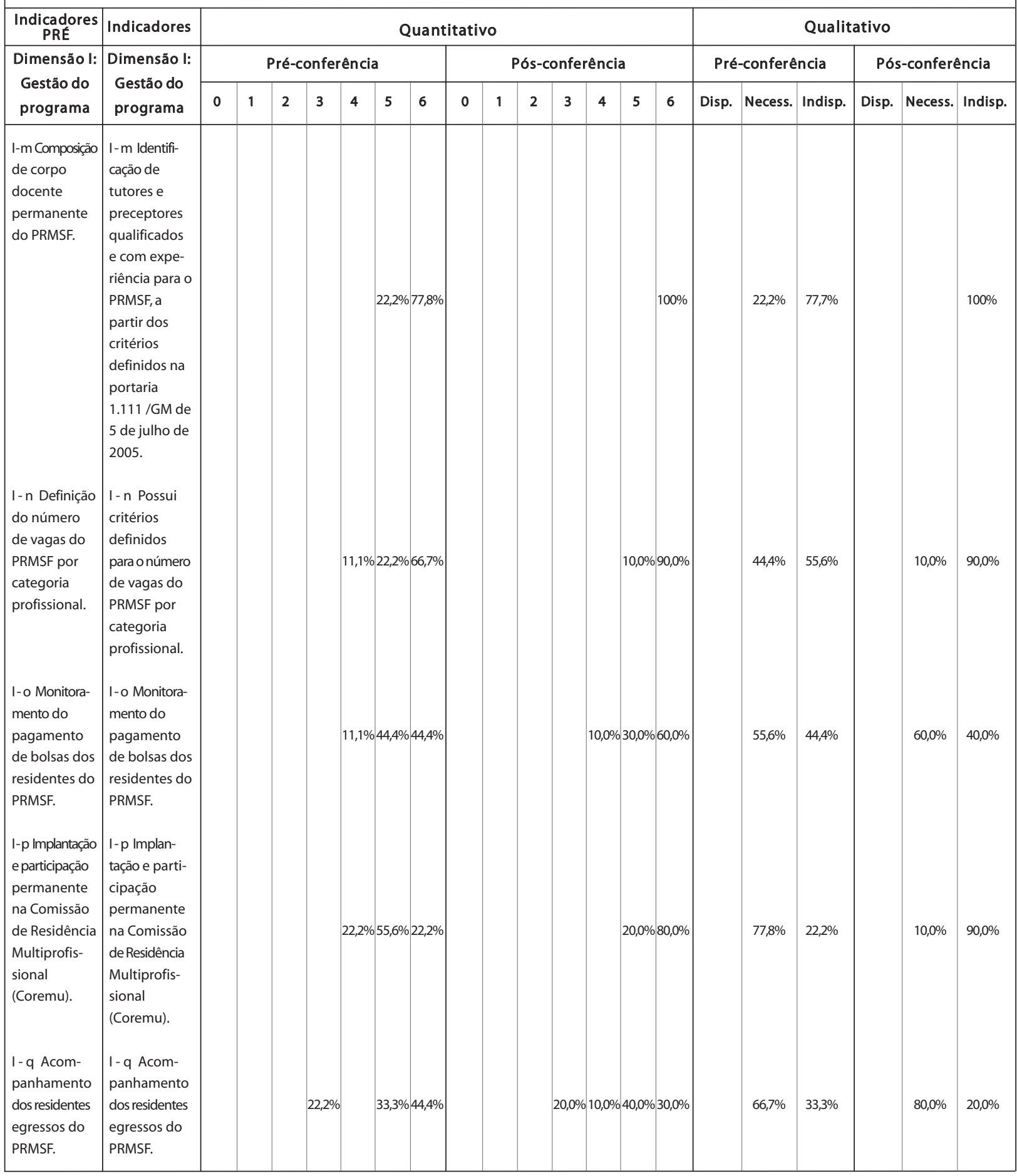


Continuação - Quadro 2

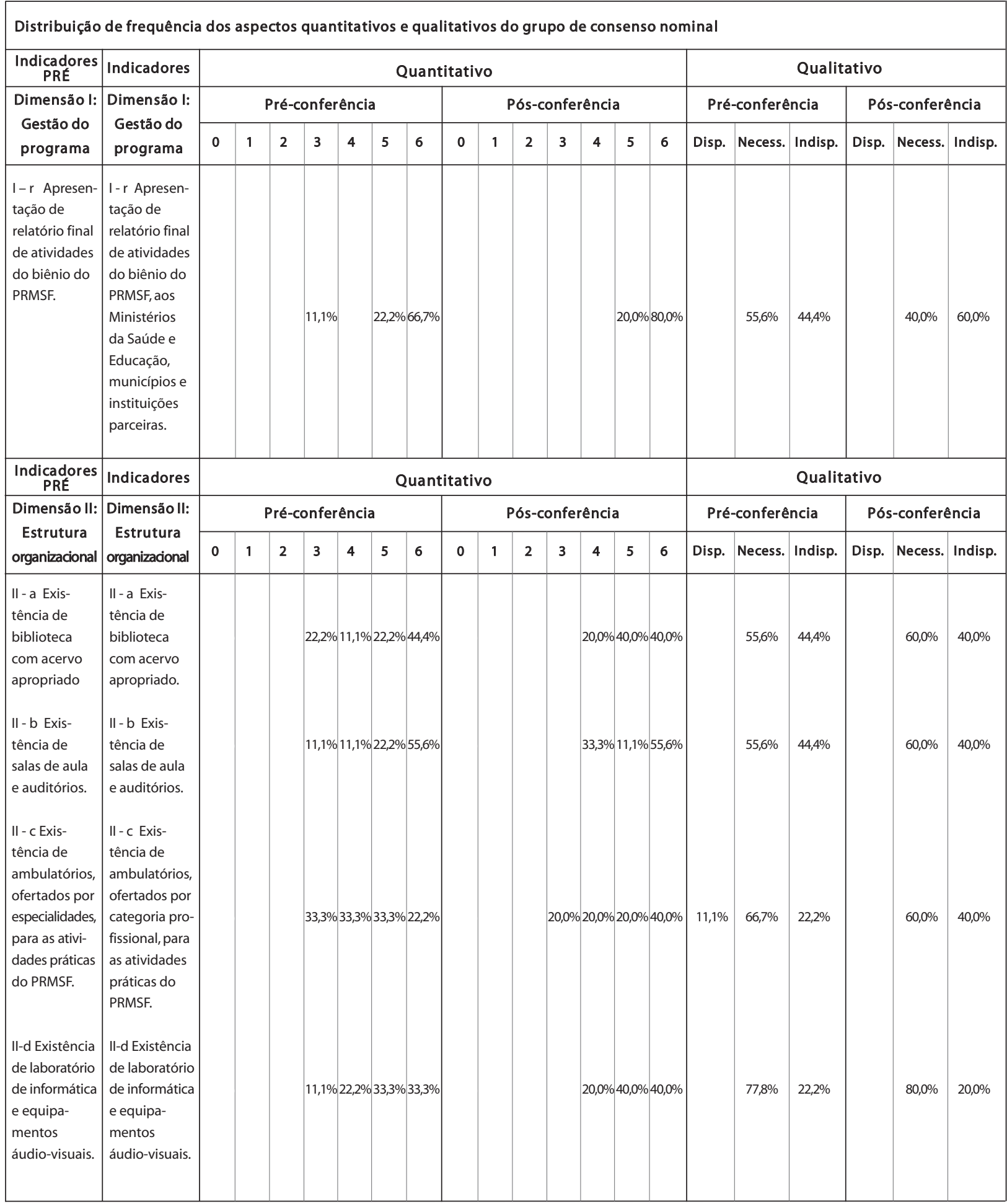


Continuação - Quadro 2

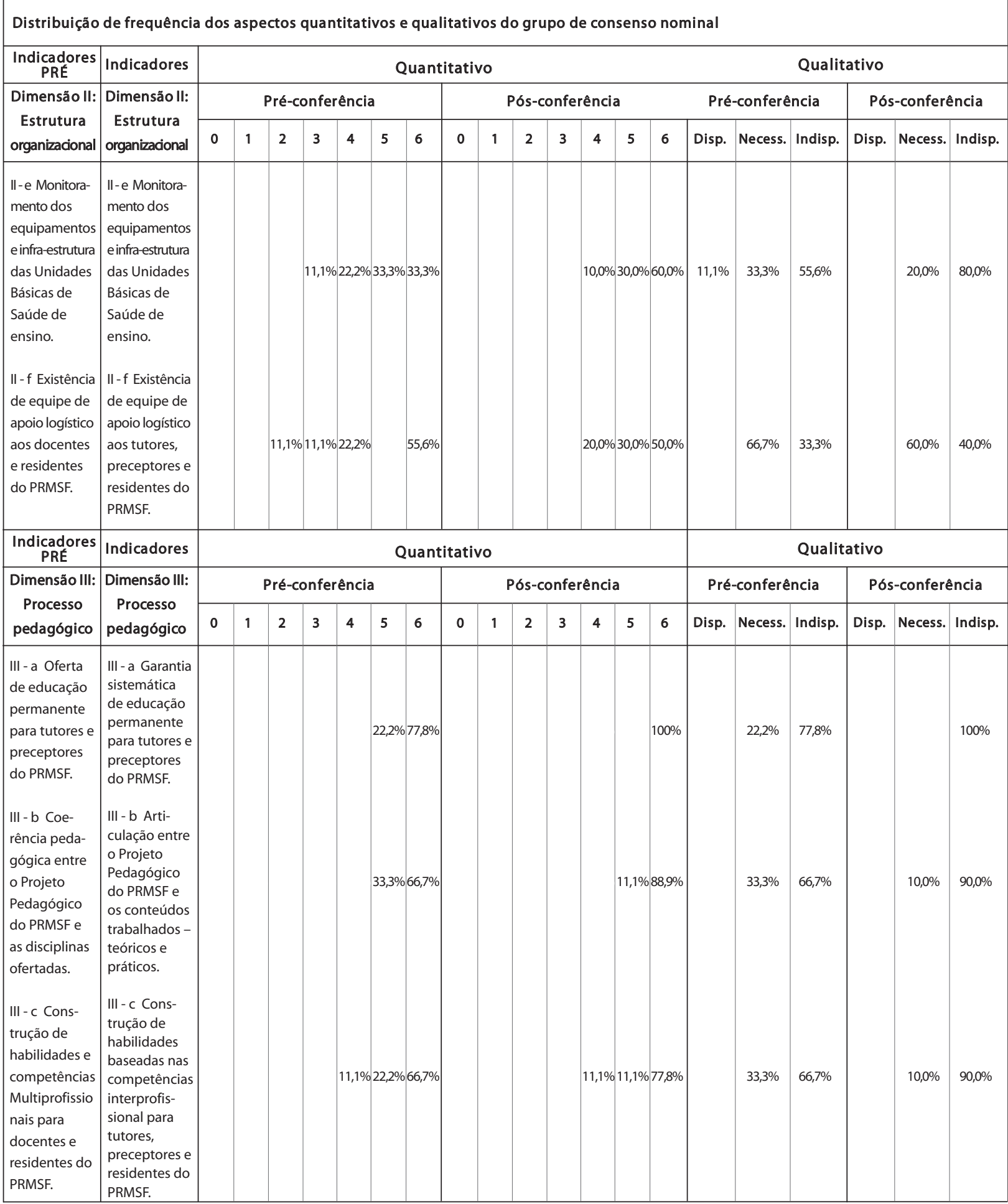


Continuação - Quadro 2

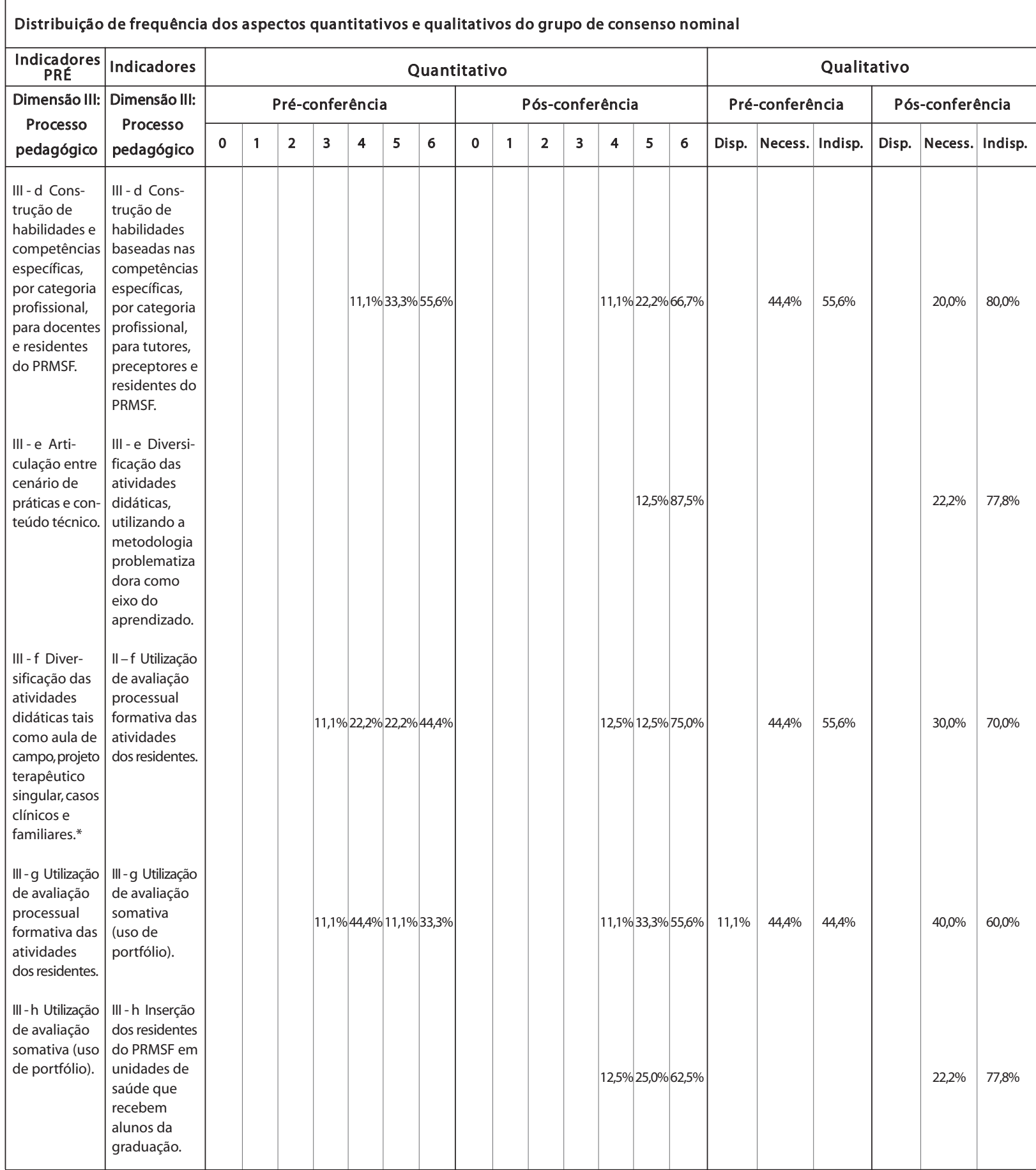

Fonte: Pesquisa direta.

Nota: Disp. - Disponível; Necess. - Necessário; Indisp. - Indisponível. 
Na dimensão I - gestão do programa -, o indicador que apresentou o maior percentual de consenso na pré-conferência, tanto na avaliação quantitativa como na qualitativa, foi o indicador I-e (Seleção pública dos candidatos ao PRMSF). Na avaliação pós-conferência, embora todos tenham sido considerados necessários ou indispensáveis, os indicadores I-c (Firmação de termo de cooperação técnica entre os municípios parceiros e a instituição de ensino superior - IES) e I-q (Acompanhamento dos residentes egressos do PRMSF) apresentaram percentuais menores que $50 \%$ na nota 6 , tendo sido ambos suprimidos do instrumento.

Na dimensão II - estrutura organizacional -, os indicadores que apresentaram o maior percentual de consenso na avaliação quantitativa - pós-conferência - foram II-b (Existência de salas de aula e auditórios) e II-e (Monitoramento dos equipamentos e infraestrutura das unidades básicas de saúde). Quanto ao de menor percentual, novamente não se encontrou uma concentração em nenhum indicador em especial. Já na avaliação qualitativa, o de maior percentual de consenso foi o II-e (Monitoramento dos equipamentos e infraestrutura das unidades básicas de saúde), e o indicador de menor percentual de consenso foi o II-d (Existência de laboratório de informática e equipamentos audiovisuais). Nessa dimensão, foram suprimidos do instrumento os indicadores IIa, IIc e IId em razão de o julgamento quantitativo ter sido inferior a $50 \%$ na nota 6 .

Na dimensão III - processo pedagógico -, os indicadores que apresentaram maior percentual de consenso na avaliação quantitativa pós-conferência foram: III-a (Garantia sistemática de educação permanente para tutores e preceptores do PRMSF); III-b (Articulação entre o Projeto Pedagógico do PRMSF e os conteúdos trabalhados - teóricos e práticos); e III-e (Diversificação das atividades didáticas utilizando a metodologia problematizadora como eixo do aprendizado). Na avaliação qualitativa, os de maior consenso foram III-a, III-b e III-c (Construção de habilidades baseadas nas competências interprofissionais para tutores, preceptores e residentes do PRMSF). Nessa dimensão, não foi suprimido nenhum indicador, pois na pós-conferência todos receberam percentual acima de 50\% na nota máxima (6). Destaca-se que foi inserido um novo indicador, o III-h (Inserção dos residentes do PRMSF em unidades de saúde que recebem alunos da graduação).

Durante a reunião de consenso, os dez atores envolvidos no processo avaliativo puderam interagir, debater e reavaliar as suas respostas em relação à reunião realizada anteriormente, por envio em meio digital. O debate presencial contribuiu efetivamente para o aperfeiçoamento dos indicadores da matriz inicial pelo grupo de acordo com sua relevância em cada uma das três dimensões, sendo alguns reformulados, excluídos ou incluídos.

Na dimensão I, dos 18 indicadores originais da matriz, reformularam-se 11 itens em sua estrutura temática, um indicador novo foi incluído e sete 
indicadores mantidos na íntegra. Um dos indicadores reformulados e outro mantido na íntegra foram suprimidos da matriz porque não obtiveram o percentual mínimo de 50\% na avaliação quantitativa. Dos 11 que foram reestruturados do ponto de vista temático, nove mantiveram sua capacidade avaliativa, tendo melhorado apenas seu entendimento semântico. Porém, em dois nos quais houve modificação no texto, ocorreu alteração da sua capacidade avaliativa original a fim de torná-los mais abrangentes. O grupo propôs, ainda, a inclusão de um novo indicador relacionado à integração dos PRMSFs com a Residência Médica em Medicina de Família e Comunidade.

Na dimensão II, o grupo expressou o maior consenso entre as proposições; reformulou a redação de apenas dois indicadores, não alterando sua capacidade avaliativa. Na dimensão III, dos oito indicadores originais, cinco foram reformulados e tiveram alteração da sua capacidade avaliativa, o que os tornou mais abrangentes, e um novo indicador foi proposto, relacionado à inserção dos residentes do PRMSF em unidades de saúde de ensino que recebiam alunos da graduação. Destaca-se ainda que o indicador da matriz original III-e (Articulação entre cenários de práticas e conteúdo teórico) foi considerado pelo grupo de especialistas como já contemplado no indicador III-b (Articulação entre o projeto pedagógico e os conteúdos trabalhados).

O estudo permitiu construir um instrumento pela técnica de consenso de experts (Quadro 3), para avaliar e discriminar quando uma estratégia de formação nos moldes do PRMSF contempla ou não os princípios e valores da atenção básica prevista pelo SUS.

O instrumento, composto pelas três dimensões anteriormente definidas, resultou em um questionário estruturado, composto por 35 perguntas avaliativas, dentre elas 32 do tipo Likert (com cinco itens de respostas, um deles de neutralidade), dois do tipo índice (dicotômica) e um de múltipla escolha para validação cruzada das respostas (Likert, 1932).

Quadro 3

Instrumento de avaliação para o Programa de Residência Multiprofissional em Saúde da Família

Dimensão I: Gestão do programa

\begin{tabular}{|l|l|}
\hline 1. Considerando os documentos normativos relativos ao PRMSF, a equipe & $\begin{array}{l}\square \text { Consultou todos os documentos normativos (portarias, comunicados, } \\
\text { que estruturou o Projeto da Residência: }\end{array}$ \\
$\begin{array}{ll}\square \text { Consultou quase todos os documentos normativos (portarias, comunicados, } \\
\text { informes) elaborados pelos Ministérios da Saúde e da Educação; } \\
\square \text { Consultou apenas os documentos essenciais à elaboração do Projeto da } \\
\text { Residência; }\end{array}$ \\
\hline
\end{tabular}


Continuação - Quadro 3

Instrumento de avaliação para o Programa de Residência Multiprofissional em Saúde da Família

Dimensão I: Gestão do programa

1. Considerando os documentos normativos relativos ao PRMSF, a equipe que estruturou o Projeto da Residência:

2. Como você classificaria o grau de envolvimento do grupo de tutores preceptores e instituições parceiras na implantação do PRMSF?

3. Há vinculação do PRMSF a uma IES?

4. Como você consideraria o envolvimento da IES no desenvolvimento do PRMS?

5. A forma de acesso dos residentes ao PRMSF acontece por meio de:

6. Como você classificaria o nível de integração (cursos, seminários, projetos, atividades comunitárias e outros) entre o PRMSF e o Programa de Residência Médica de Medicina de Família e Comunidade?

7. O PRMSF prevê e realiza avaliação sistemática ao longo do seu desenvolvimento? $\square$ Consultou apenas a portaria interministerial n. 1.077, de 12 de novembro de 2009;

$\square$ Não consultou nenhum documento normativo (portarias, comunicados, informes) elaborado pelos Ministérios da Saúde e da Educação.

$\square$ Não houve envolvimento do grupo;

$\square$ O envolvimento do grupo foi indiferente para a implantação do PRMSF;

$\square$ Houve envolvimento incipiente;

$\square$ Houve envolvimento parcial do grupo;

$\square$ Houve um envolvimento decisivo do grupo para a implantação do PRMSF.

$\square \mathrm{SIM}$

$\square \mathrm{NÃO}$

$\square$ Não houve envolvimento da IES;

$\square$ O envolvimento da IES foi indiferente para o desenvolvimento do PRMSF;

$\square$ Houve envolvimento incipiente;

$\square$ Houve envolvimento parcial da IES;

$\square$ Houve um envolvimento decisivo da IES para o desenvolvimento do PRMSF.

$\square$ Todos por meio de seleção pública;

$\square$ Todos por indicação da IES à qual o PRMSF está vinculado, com critérios predefinidos;

$\square$ Por meio de seleção pública e de indicação da IES;

$\square$ Todos por indicação da IES à qual o PRMSF está vinculado, sem critérios predefinidos;

$\square$ Por ordem de inscrição no PRMSF.

$\square$ Não existe integração entre o PRMSF e o Programa de Residência Médica de Medicina de Família e Comunidade;

$\checkmark$ Existe pouca integração entre o PRMSF e o Programa de Residência Médica de Medicina de Família e Comunidade;

$\checkmark$ Existe integração regular entre o PRMSF e o Programa de Residência Médica de Medicina de Família e Comunidade;

$\square$ Existe muita integração entre o PRMSF e o Programa de Residência Médica de Medicina de Família e Comunidade;

$\square$ Existe total integração entre o PRMSF e o Programa de Residência Médica de Medicina de Família e Comunidade.

$\square$ Não são previstas nem realizadas avaliações ao longo do desenvolvimento do PRMSF;

$\square$ Avaliações são previstas, mas não realizadas ao longo do desenvolvimento do PRMSF;

$\square$ Avaliações são previstas e realizadas esporadicamente ao longo do desenvolvimento da estratégia; 
Continuação - Quadro 3

Instrumento de avaliação para o Programa de Residência Multiprofissional em Saúde da Família

Dimensão I: Gestão do programa

7. O PRMSF prevê e realiza avaliação sistemática ao longo do seu desenvolvimento?

8. Em relação à avaliação sistemática do PRMSF, como você classificaria a participação do grupo de tutores, preceptores, residentes e instituições parceiras?

9. O PRMSF garante ao grupo de tutores, preceptores e residentes o acesso a material didático, por meio das diversas mídias?

10. Para um bom desenvolvimento do PRMSF se faz necessária a existência de uma escolaridade efetiva (emissão de certificados e declarações, controle de frequências, entre outros). Como você classificaria esse tipo de serviço no seu PRMSF?

11. O PRMSF utiliza o Sistema de Informação Gerencial dos Programas de Residências-MEC (SIG-Residência) para o acompanhamento do programa?

12. Como você classificaria a qualificação e experiência do coordenador/supervisor do PRMSF?

13. Qual o grau de participação do grupo de representantes de tutores, preceptores, residentes e instituições parceiras do programa na elaboração e aprovação do regimento interno do PRMSF? $\square$ Avaliações são previstas e realizadas ao longo do desenvolvimento do PRMSF;

$\square$ Avaliações são previstas e realizadas continuamente ao longo do PRMSF.

$\square$ Não existe participação do grupo no processo de avaliação sistemática do PRMSF;

$\square$ Existe pouca participação do grupo no processo de avaliação sistemática do PRMSF;

$\square$ Existe participação regular do grupo no processo de avaliação sistemática do PRMSF;

$\square$ Existe muita participação do grupo no processo de avaliação sistemática do PRMSF;

$\square$ Existe total participação do grupo no processo de avaliação sistemática do PRMSF

$\square$ Nenhum material didático é garantido;

$\square$ Apenas o material impresso é garantido, quando solicitado pelo grupo; $\square$ Material de diversas mídias é garantido, quando solicitado pelo grupo;

$\square$ Todo o material impresso é garantido, independentemente da solicitação do grupo;

$\square$ Todo o material de diversas mídias é garantido (TV, DVD, data show, material impresso, internet, CDs etc.)

$\square$ Não existe o serviço de escolaridade;

$\square$ Ruim;

$\square$ Regular;

$\square$ Bom;

$\square$ Ótimo.

$\square \mathrm{SIM}$

$\square \mathrm{NÃO}$

$\square$ Muito experiente e muito qualificado;

$\checkmark$ Muito experiente e pouco qualificado;

$\square$ Regular experiência e regular qualificação;

$\square$ Pouco experiente e pouco qualificado;

$\square$ Nem experiente nem qualificado.

$\square$ Não existe participação do grupo na elaboração e aprovação do regimento interno do PRMSF;

$\square$ Existe pouca participação do grupo na elaboração e aprovação do regimento interno do PRMSF;

$\square$ Existe participação regular do grupo na elaboração e aprovação do regimento interno do PRMSF;

$\square$ Existe muita participação do grupo na elaboração e aprovação do regimento interno do PRMSF; 
Continuação - Quadro 3

Instrumento de avaliação para o Programa de Residência Multiprofissional em Saúde da Família

Dimensão I: Gestão do programa

13. Qual o grau de participação do grupo de representantes de tutores, preceptores, residentes e instituições parceiras do programa na elaboração e aprovação do regimento interno do PRMSF?

14. Como você classificaria a utilização do regimento interno como instrumento norteador das ações do PRMSF?

15. Tomando como referência as definições/conceitos sobre os tutores e preceptores referidos na portaria n. 1.111/GM, de 5 de julho de 2005, qual o percentual do total de tutores e preceptores do PRMSF que você consideraria experiente e qualificado?

16. A distribuição do número de vagas por categoria profissional do PRMSF pode adotar critérios predefinidos (necessidade locorregional, perfil epidemiológico, demanda de candidatos e outros). Essa distribuição ocorre:

17. Como você classificaria o monitoramento do pagamento das bolsas dos residentes do PRMSF?

18. Como você avalia a participação do grupo de tutores, preceptores, residentes e instituições parceiras na Comissão de Residência Multiprofissional em Saúde (Coremu)?

19. Qual das alternativas representa a instância/órgão/comissão que tem acesso ao relatório de atividades do biênio do PRMSF? $\square$ Existe total participação do grupo na elaboração e aprovação do regimento interno do PRMSF.

$\square$ Sua utilização é sistemática;

口 Sua utilização é eventual/pontual;

$\square$ Sua utilização acontece apenas quando é demandada/solicitada;

$\square$ Sua utilização dificilmente acontece (é rara);

$\square$ Sua utilização nunca acontece.

$\square$ Menor de 20\%;

口 Entre 20\% e 40\%;

$\square$ Entre $40 \%$ e $60 \%$;

들 $60 \%$ e $80 \%$;

口 Maior de $80 \%$.

$\square$ Sem o estabelecimento de critérios predefinidos;

$\square$ Com o estabelecimento de critérios predefinidos para poucas categorias profissionais;

$\square$ Com o estabelecimento de critérios predefinidos parciais para todas as categorias profissionais;

$\square$ Com o estabelecimento de critérios predefinidos para quase todas as categorias profissionais;

$\square$ Com o estabelecimento de critérios predefinidos para todas as categorias profissionais.

$\square$ Não existe monitoramento;

$\square$ Ruim;

$\square$ Regular;

$\square$ Bom;

$\square$ Ótimo.

$\square$ O PRMSF não possui Coremu implantada;

$\square$ Existe pouca participação do grupo na Coremu

$\square$ Existe uma participação regular do grupo na Coremu;

$\square$ A maioria do grupo participa da Coremu;

$\square$ Existe participação efetiva de todo o grupo na Coremu.

$\square$ Todos os parceiros ao final de cada biênio;

$\square$ Apenas o órgão financiador;

$\square$ O parceiro financiador e a Coremu;

$\square$ Apenas a Coremu;

$\square$ O relatório é apenas para conhecimento interno. 
Continuação - Quadro 3

Instrumento de avaliação para o Programa de Residência Multiprofissional em Saúde da Família

Dimensão II: Estrutura organizacional

\begin{tabular}{|c|c|c|c|c|c|}
\hline Aspectos & Não existe & Ruim & Regular & Bom & Otimo \\
\hline $\begin{array}{l}\text { 20. Salas de aula } \\
\text { 21. Auditórios } \\
\text { 22. Monitoramento dos equipamentos das USFs de ensino } \\
\text { 23. Monitoramento da infraestrutura das USFs de ensino } \\
\text { 24. Equipe de apoio logístico aos tutores, preceptores e residentes }\end{array}$ & & & & & \\
\hline
\end{tabular}

Dimensão III: Processo pedagógico

25. Em relação à educação permanente para tutores e preceptores do PRMSF:

26. Como você avalia a articulação entre o projeto pedagógico do PRMSF e os seus conteúdos trabalhados (teóricos e práticos)?

27. Quais dos itens abaixo são utilizados para integrar o projeto pedagógico do PRMSF com os seus conteúdos trabalhados (teóricoprático):

Observação: Nesta questão você pode marcar quantos itens achar necessário. $\square$ A educação permanente não é ofertada para os tutores e preceptores do PRMSF;

$\square$ A educação permanente é ofertada de modo pontual por demanda dos tutores e preceptores;

$\square$ A educação permanente é ofertada de modo pontual por demanda do PRMSF;

$\square$ A educação permanente é ofertada para a maioria dos tutores e preceptores;

$\square$ A educação permanente é ofertada de modo sistemático para todos os tutores e preceptores.

\ Não existe articulação entre o projeto pedagógico do PRMSF e os seus conteúdos trabalhados (teóricos e práticos):

$\square$ Ruim;

$\square$ Regular;

$\square$ Bom;

口Ótimo.

๑ Semana padrão do residente (núcleo multiprofissional);

口 Semana padrão do residente (núcleo específico);

口 Projeto de intervenção dos residentes;

口 Discussão de casos clínicos e familiares;

$\checkmark$ Clube de periódicos;

๑ Seminários de núcleo multiprofissional;

$\square$ Seminários de núcleo específico;

$\square$ Atividades teóricas (modulares e/ou isoladas);

$\square$ Atividades práticas ambulatoriais;

$\square$ Atividades práticas nas comunidades;

$\square$ Monografias/artigos científicos;

$\square$ Atividades de docência (graduação);

$\square$ Atividades de pesquisa;

口Estágio curricular e/ou opcional nas áreas de gestão, ensino, pesquisa e extensão comunitária. 
Continuação - Quadro 3

Instrumento de avaliação para o Programa de Residência Multiprofissional em Saúde da Família

Dimensão III: Processo pedagógico

28. Como você avalia a construção de habilidades baseadas nas

competências interprofissionais para tutores, preceptores e residentes do PRMSF?

29. Como você avalia a construção de habilidades baseadas nas competências específicas por categoria profissional para tutores, preceptores e residentes do PRMSF?

30. Qual o percentual das atividades didáticas do PRMSF que utiliza aulas expositivas como método pedagógico?

31. Qual o percentual das atividades didáticas do PRMSF que utiliza metodologia ativa de aprendizagem como método pedagógico?

32. O PRMSF prevê a realização de avaliações ao longo do seu desenvolvimento (formativa)?

33. O PRMSF prevê a realização de avaliações ao final do seu desenvolvimento (somativa)? $\square$ Não existe a construção de habilidades baseadas nas competências interprofissionais;

$\square$ Ruim;

$\square$ Regular;

$\square$ Bom;

口Ótimo.

$\square$ Não existe a construção de habilidades baseadas nas competências específicas;

$\square$ Ruim;

$\square$ Regular;

$\square$ Bom;

$\square$ Ótimo.

口 Menor de 20\%;

Entre 20\% e 40\%;

口 Entre $40 \%$ e $60 \%$;

口 Entre 60\% e 80\%;

口 Maior de $80 \%$.

$\square$ Menor de 20\%;

口 Entre $20 \%$ e $40 \%$;

口 Entre $40 \%$ e $60 \%$;

口 Entre $60 \%$ e $80 \%$;

口 Maior de $80 \%$.

$\square$ Não são previstas nem realizadas avaliações ao longo do desenvolvimento do PRMSF;

$\square$ Avaliações são previstas, mas não realizadas, ao longo do desenvolvimento do PRMSF;

$\square$ Avaliações são previstas e realizadas esporadicamente ao longo do desenvolvimento do PRMSF;

$\square$ Avaliações são previstas e realizadas ao longo do desenvolvimento do PRMSF;

$\square$ Avaliações são previstas e realizadas sistematicamente ao longo do desenvolvimento do PRMSF.

$\square$ Não são previstas nem realizadas avaliações ao final do PRMSF;

$\square$ Avaliações são previstas, mas não realizadas, ao final do PRMSF;

$\square$ Avaliações são previstas e realizadas esporadicamente ao final do PRMSF;

$\square$ Avaliações são previstas e realizadas ao final do desenvolvimento do PRMSF;

$\square$ Avaliações são sempre previstas e realizadas ao final do

desenvolvimento do PRMSF. 
Continuação - Quadro 3

\begin{tabular}{|c|c|}
\hline \multicolumn{2}{|c|}{ Dimensão III: Processo pedagógico } \\
\hline $\begin{array}{l}\text { 34. Qual o percentual das atividades pedagógico-didáticas que utiliza o } \\
\text { portfólio como instrumento avaliativo? } \\
\text { 35. Qual o percentual de residentes do PRMSF que recebe alunos da } \\
\text { graduação nas suas respectivas USFs de ensino? }\end{array}$ & 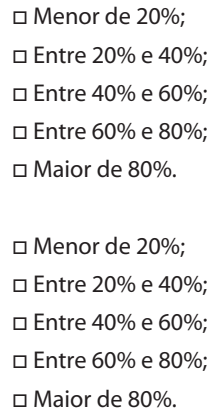 \\
\hline
\end{tabular}

Fonte: Elaboração dos autores.

\section{Discussão}

O estudo apresentou o processo de construção de um instrumento avaliativo, cumprindo objetivos preestabelecidos e com metodologia definida. Recebeu imprescindível contribuição dos membros da reunião de consenso, os quais sugeriram reformulação e inclusão de novos indicadores à matriz. Tais aspectos conferiram validade ao modelo lógico e à matriz de indicadores para avaliação do Programa de Residência Multiprofissional em Saúde, com foco na Estratégia Saúde da Família (Goes, 2006; Bezerra et al., 2012; Tamaki et al., 2012).

É visão corrente que os profissionais de saúde não têm sido formados com os conhecimentos, habilidades, atitudes e valores suficientes para o adequado desempenho no SUS. Estudos assinalam a crise na formação e no desenvolvimento dos recursos humanos. Essa crise relaciona-se às mudanças relativas ao mercado de trabalho, organização dos serviços, especialização precoce e sem limites, desarticulação ensino-serviço e desintegração dos aspectos biológico-social, básico-profissional e individual-coletivo (Conselho Nacional de Secretários de Saúde, 2006).

Campos e Aguiar (2005) afirmam que a qualificação dos profissionais de nível superior da Estratégia Saúde da Família, por meio de residências médicas e residências multiprofissionais de saúde, é fator necessário na consolidação desse modelo. Os autores a consideram uma opção importante para reduzir os efeitos de uma formação inadequada para os agentes técnicos já inseridos no sistema de saúde.

Ao se considerarem as três dimensões deste estudo - gestão do programa, estrutura organizacional e processo pedagógico -, as que receberam maior 
número de sugestões para modificações na matriz de indicadores foram a dimensão I (gestão do programa) e a III (processo pedagógico). Na primeira, destacou-se a avaliação inicial para o consenso segundo o qual os indicadores foram identificados como necessário e indispensável; na segunda, nenhum indicador tornou-se dispensável. Não houve, portanto, nessa dimensão, mudanças significativas nos indicadores quanto à caracterização e à capacidade avaliativa. Ressalta-se, aqui, a importância do foco em nível gerencial para que os programas adquiram efetividade, ao se considerar que o subfinanciamento, por ser uma questão político-orçamentária e tratada em diferentes níveis de gestão e de governo, tem sido uma questão persistentemente crítica ao longo do tempo (Conselho Nacional de Secretários de Saúde, 2006).

Por sua vez, a grande quantidade de contribuições relativas à dimensão III, não só em termos semânticos como também em relação à ampliação da capacidade avaliativa, foi o que mais se destacou no método de construção do instrumento aqui proposto. Em estudo com metodologia semelhante realizado em 2005, os aspectos relacionados ao núcleo do objeto da pesquisa foram os pontos de maior divergência e com maior consenso e contribuições do grupo. Isso também ocorreu no presente trabalho, uma vez que a dimensão relacionada ao projeto pedagógico, eixo central do objeto, obteve o maior número de contribuições do grupo de experts (Souza, Vieira-da-Silva e Hartz, 2005).

Também houve o reconhecimento de que os profissionais de saúde precisam ser formados de acordo com um novo paradigma, ou seja, um processo pedagógico no qual ocorra uma crítica ao paradigma cartesiano e biomédico que ainda predomina na maioria das instituições formadoras. Surge daí a necessidade de se ampliarem debates suscitados ora pelo SUS ora pelas IES, para revisarem as suas práticas pedagógicas (Brasil, 2005; Felisberto et al., 2008, 2010). Tais inquietações foram traduzidas no presente estudo pelas contribuições que ocorreram na dimensão III.

Outro fator identificado foi a atenção dada pelo grupo às ações voltadas para o estímulo à educação permanente. Esta foi apresentada como um dos sustentáculos da articulação entre os diversos esforços de formação para os profissionais de saúde no Brasil, em razão da possibilidade de eles terem a oportunidade de gerar reflexão com base no seu processo de trabalho, propiciando novos conhecimentos e aperfeiçoamento do cuidado ofertado aos usuários (Brasil, 2005; Campos, Aguiar e Belisário, 2008). Esse achado refletiu a preocupação do grupo em priorizar a análise dos indicadores referentes ao projeto pedagógico, embasado em estratégias de problematização e na articulação entre cenários teóricos e práticos (Morin, 2003; Felisberto et al., 2008).

Em outros estudos, nos quais metodologia semelhante foi empregada, utilizaram-se medidas de tendência central para a análise. Neste, a valorização percentual dos itens que alcançavam maiores escores pareceu mais opor- 
tuna, diante do fato de não existirem dados prévios de outros estudos que permitissem uma análise comparativa de medidas de tendência central e dispersão sobre o mesmo objeto. Assim, a técnica de consenso escolhida possibilitou que, ao mesmo tempo que se estimulava a busca de consenso genuíno, houvesse uma ampla discussão de especialistas; se preservasse o anonimato dos participantes; e fosse de fácil realização na busca por uma troca estruturada de informações (Carr-Hiel, 1992; Cassiani e Rodrigues, 1996).

Em vez de se utilizar uma 'imagem objetivo', formulou-se um modelo lógico, dados a dimensão programática e o forte conteúdo que rege o objeto. Isso possibilitou a construção de uma matriz que forneceu a base de análise para obtenção do consenso, não sendo utilizadas etapas intermediárias como ocorrem em outras técnicas metodológicas (Souza, Vieira-da-Silva e Hartz, 2005; Reis, 2010).

Algumas limitações precisam ser sublinhadas à observação dos resultados deste estudo. Uma delas diz respeito à validação de face do instrumento construído, uma vez que a sua não realização estava diretamente relacionada ao tempo de realização do curso de mestrado profissional, do qual este artigo constituiu-se em produto final. Nesse sentido, lembramos que alguns autores defendem a ideia de que a própria aplicação da técnica per si já se constitui em um dos passos no processo de validação de matrizes e instrumentos de avaliação (Goes, 2006; Reis, 2010). Outra questão limitante foi o caráter regional dos participantes do consenso, uma vez que fatores externos contribuíram para que atores de nível nacional convidados declarassem impossibilidade de comparecimento à reunião de experts. Dessa forma, as discussões ocorreram em um universo muito semelhante sem aprofundar as diferenças regionais do país. No entanto, serviu como atenuante a forma fidedigna como o método foi aplicado, o que possibilitou otimizar as contribuições dos atores participantes.

É necessário destacar o envolvimento dos experts com o tema, o que provavelmente favoreceu a elaboração de uma matriz de indicadores coerente com o modelo lógico proposto, consequentemente com a ocorrência não de sugestões de mudanças substanciais, mas sim de um trabalho de aperfeiçoamento na composição da matriz final.

\section{Considerações finais}

O uso da avaliação como possibilidade de criação de espaços para reflexão das práticas dos profissionais de saúde, ou dos atores envolvidos no programa ou serviço, tem sido apresentado de acordo com cinco componentes: busca de identidades; transferência de poder; busca por motivação; desenvolvimento de competências para avaliação; e alocação de recursos, conforme Silva e 
Brandão (2003) e Felisberto e colaboradores (2008). Nesse sentido, a disponibilização de um instrumento avaliativo consistente em uma proposta de pós-graduação lato sensu poderá contribuir para o processo de institucionalização da avaliação em serviços e centros formadores. Sua utilização pode oportunizar a melhoraria da qualidade dos serviços ofertados aos seus usuários por intermédio de profissionais formados em consonância com os princípios e diretrizes do SUS, corroborando Felisberto e colaboradores $(2008 ; 2010)$ e Costa e colaboradores $(2013)$.

A existência de instrumentos avaliativos confiáveis para identificar os fatores que exercem influência nas práticas do Programa de Residência Multiprofissional em Saúde da Família é importante tanto para a tomada de decisão quanto para a elaboração de intervenções efetivas para a melhoria da formação dos profissionais do SUS. O instrumento ora apresentado deve ser adaptado às necessidades e realidades locais com a inclusão ou exclusão de indicadores, a depender do contexto locorregional. Faz-se importante ainda a revisão periódica do modelo lógico, visando à sua adequação para contemplar novos aspectos ou outros não previstos que aparecem com o aprimoramento dos processos pedagógicos e inovações que ocorrem no sistema (Costa et al., 2013).

\section{Colaboradores}

Tereza Cristina Alves Bezerra trabalhou na concepção, delineamento e redação do artigo. Maria Leopoldina Padilha Falcão e Eronildo Felisberto, na concepção, redação e revisão crítica. Paulo Sávio Angeiras de Goes, na redação final e revisão crítica. Não houve financiamento e não há conflito de interesses. 
Resumen Este artículo tuvo como objetivo preparar un instrumento calificador apuntando a construir para el monitoreo y la evaluación del Programa de Residencia Multiprofesional en Salud de la Familia. Fue un estudio de evaluación exploratorio desarrollado en dos fases: la primera, constituida por la construcción y validación de la comprensión del modelo lógico y de la matriz de indicadores, por medio de análisis documental y de la técnica de consenso grupo nominal. Esta primera fase, a su vez, tuvo lugar en dos momentos, pre y post reunión de consenso, en los cuales se buscó validar un modelo lógico y una matriz de indicadores que reflejaran los principales elementos de evaluación del programa. La segunda fase comprendió la construcción del instrumento de evaluación. A partir del grupo de consenso, se validaron un modelo lógico y la matriz de indicadores, lo que resultó en 32 indicadores, utilizados para la construcción del instrumento de evaluación que se formató mediante cuestionario estructurado. Este cuestionario estaba compuesto por 35 preguntas de evaluación distribuidas en 19 preguntas en la dimensión gestión del programa; cinco en la dimensión estructura organizacional y 11 en la dimensión proceso pedagógico. El instrumento preparado, basado en protocolo de aceptación universal para esa finalidad, deberá ser aplicado en futuras investigaciones para completar su proceso de validación. Palabras clave evaluación de programas; gestión pública; Estrategia Salud de la Familia; formación profesional en salud.

\section{Notas}

${ }^{1}$ Instituto de Medicina Integral Professor Fernando Figueira, Recife, Pernambuco, Brasil.

$<$ tereza2911@hotmail.com>

Correspondência: Rua dos Coelhos, 300, Boa Vista, CEP 50070-550, Recife, Pernambuco, Brasil.

2 Instituto de Medicina Integral Professor Fernando Figueira, Recife, Pernambuco, Brasil.

<leopoldina.falcao@gmail.com>

3 Universidade Federal de Pernambuco, Recife, Pernambuco, Brasil.

<paulosaviogoes@gmail.com>

4 Instituto de Medicina Integral Professor Fernando Figueira, Recife, Pernambuco, Brasil.

<eronildo.felisberto@gmail.com>

${ }^{5}$ Este artigo resulta de dissertação de mestrado profissional em Avaliação em Saúde, intitulada Programa de residência multiprofissional em saúde: construção de um instrumento avaliativo, de autoria de Tereza Cristina Bezerra, apresentada ao Instituto de Medicina Integral Professor Fernando Figueira (Imip), no Recife, Pernambuco, em fevereiro de 2011. 


\section{Referências}

ALVES, Cintia K. et al. Interpretação e análise das informações: o uso de matrizes, critérios, indicadores e padrões. In: SAMICO, Isabella et al. Avaliação em saúde: bases conceituais e operacionais. Rio de Janeiro: Medbook, 2010. p. 89-107.

BEZERRA, Luciana C. A. et al. Identificação e caracterização dos elementos constituintes de uma intervenção: pré-avaliação da política ParticipaSUS. Ciência \& Saúde Coletiva, Rio de Janeiro, v. 17, n. 4, p. 883-900, 2012.

BRASIL. Ministério da Saúde. Secretaria de Políticas de Saúde. Departamento de Atenção Básica. Construção cotidiana. Revista Brasileira Saúde da Família, Brasília, n. 4, p. 4-10, jan. 2002.

BRASIL. Ministério da Saúde. Secretaria de Gestão do Trabalho e Educação na Saúde. Departamento de Gestão da Educação na Saúde. Educação na saúde. Brasília: Ministério da Saúde, 2005. (Série C; Projetos, Programas e Relatórios).

BRASIL. Ministério da Saúde. Secretaria de Gestão do Trabalho e Educação na Saúde. Residência multiprofissional em saúde: experiências, avanços e desafios. Brasília: Ministério da Saúde, 2006.

BRASIL. Ministério da Saúde. Portaria GM n. 227, de 16 de fevereiro de 2001. Diário Oficial da União, 19 de fevereiro de 2001, Seção 1, p. 87.

BRASIL. Ministério da Saúde. Portaria interministerial MS/ME n. 2.117, de 3 de novembro de 2005. Diário Oficial da União, 4 de novembro de 2005a, n. 212, Seção 1, p. 112.

BRASIL. Ministério da Saúde. Portaria interministerial MS/GM n. 2.118, de 3 de novembro de 2005. Diário Oficial da União, 4 de novembro de 2005b, n. 212, Seção 1, p. 112.

BRASIL. Ministério da Saúde. Portaria interministerial MS/ME n. 506, de 24 de abril de
2008. Diário Oficial da União, de 25 de abril de 2008a, n. 79, Seção 1, p. 12.

BRASIL. Ministério da Saúde. Portaria interministerial MS/ME n. 1, de 24 de fevereiro de 2010. Disponível em: <http://bvsms. saude.gov.br/bvs/saudelegis/sgtes/2010/ prt0001_05_02_2010.html>. Acesso em: 25 mar. 2016.

BRASIL. Ministério da Educação. Portaria interministerial MEC/MS n. 45 de 12 de Janeiro de 2007. Disponível em: <http:// portal.mec.gov.br/sesu/arquivos/pdf /residencia/portaria_45_2007.pdfem >. Acesso em: 25 mar. 2016.

BRASIL. Ministério da Educação. Portaria interministerial MEC/MS n. 506, de 24 de abril de 2008. Diário Oficial da União, 25 de abril de 2008b, Seção 1, p. 12.

BRASIL. Ministério da Educação. Portaria interministerial MEC/MS n. 1077, de 12 de novembro de 2009. Diário Oficial da União, 13 de novembro de 2009, Seção 1, p. 1 .

CAMPOS, Francisco E.; AGUIAR, Raphael A. T. A expansão da atenção básica nas grandes cidades e a especialização em saúde da família como estratégia para sua viabilidade. Revista Brasileira de Saúde da Família, Brasília, v. 8, n. 6, p. 38-46, 2005

CAMPOS, Francisco E.; AGUIAR, Raphael A. T.; BELISÁRIO, Soraya A. A formação superior dos profissionais de saúde. In: GIOVANELLA, Ligia et al. Politicas e sistema de saúde no Brasil. Rio de Janeiro: Editora Fiocruz, 2008. p. 1.011-1.034.

CARR-HIEL, Roy A. The measurement of patient satisfaction. Journal of Public Health, Oxford, v. 14, n. 3, p. 236-249, 1992.

CASSIANI, Silvia H. B.; RODRIGUES, Liliane P. A técnica de Delfos e a técnica de grupo nominal como estratégias de coleta de dados das pesquisas em enfermagem. 
Acta Paulista de Enfermagem, São Paulo, v. 9, n. 2, p. 76-83, 1996.

\section{CONSELHO NACIONAL DE SECRETÁRIOS} DE SAÚDE (CONASS). SUS: avanços e desafios. Brasília: Conass, 2006.

COSTA, Juliana M. B. S. et al. Monitoramento do desempenho da gestão da vigilância em saúde: instrumento e estratégias de uso. Ciência \& Saúde Coletiva, Rio de Janeiro, v. 18, n. 5, p 1.201-1.216, 2013.

FELISBERTO, Eronildo et al. Uso da avaliação e formação profissional: impulsionando a prática da integralidade em saúde. In: PINHEIRO, Roseni; SILVA JÚNIOR, Aluisio G.; MATTOS, Ruben A. (orgs.). Atenção básica e integralidade: contribuições para estudos das práticas avaliativas em saúde. Rio de Janeiro: Cepesc, 2008. p. 59-72.

FELISBERTO, Eronildo et al. Institucionalização da Avaliação. In: SAMICO, Isabella et al. (orgs.). Avaliação em saúde: bases conceituais e operacionais. 1. ed. Rio de Janeiro: Medbook, 2010, p. 143-160. (Volume 1).

FELISBERTO, Eronildo et al. Institucionalização da Avaliação em Saúde. In: GOES, Paulo S. A.; MOYSÉS, Samuel J. (org.). Planejamento, gestão e avaliação em Saúde Bucal. 1. ed. São Paulo: Artes Médicas, 2012. p. 149-156. (Volume 1).

GOES, Paulo S. A. Validação de instrumento de coleta de dados. In: PEREZ, Marcos A.; ANTUNES, José L. F. Epidemiologia da saúde bucal. Rio de Janeiro: Guanabara Koogan, 2006. p. 229-645.

HARTZ, Zulmira M. A. Avaliação dos programas de saúde: perspectivas teórico-metodológicas e políticas institucionais. Ciência \& Saúde Coletiva, Rio de Janeiro, v. 4, n. 2, p. 341-353, 1999.

JONES, Jeremy; HUNTER, Duncan. Consensus methods for medical and health services research. In: MAYS, Nicholas; POPE, Catherine. Qualitative research in health care. London: BMJ Publishing Group, 1995, n. 311, p. 376-380.
LIKERT, Rensis. A technique for the measurement of attitudes. Archives of Psychology, New York, n. 140, p. 1-55, 1932.

MCLAUGHLIN, John A.; JORDAN, Gretchen B. Logic models: a tool for telling your program's performance story. Eval Program Plann, Amsterdam, n. 22, p. 65-72, 1999.

MEDINA, Maria G. et al. Uso de modelos teóricos na avaliação em saúde: aspectos conceituais e operacionais. In: HARTZ, Zulmira M. A.; VIEIRA-DA-SILVA, Lígia M. Avaliação em saúde: dos modelos teóricos à prática na avaliação de programas. Rio de Janeiro: Editora Fiocruz, 2005. p. 41-74.

MORIN, Edgard. A cabeça bem-feita: repensar a reforma, reformar o pensamento. 8. ed. Rio de Janeiro: Bertrand Brasil, 2003.

NASCIMENTO, Débora D. G.; OLIVEIRA, Maria A. C. Competências profissionais e o processo de formação na Residência Multiprofissional em Saúde da Família. Saúde e Sociedade, São Paulo, v. 19, n. 4, p. 814-827, 2010.

PAGLIOSA, Fernando L.; DA ROS, Marco A. O relatório Flexner: para o bem e para o mal. Revista Brasileira de Educação Médica, Rio de Janeiro, v. 32, n. 4, p. 492-499, 2008.

REIS, Yluska A. C. Consensos sobre o papel do gestor estadual na regionalização da assistência à saúde do SUS. Dissertação (Mestrado em Ciências) - Fundação Oswaldo Cruz, Centro de Pesquisas Aggeu Magalhães, Recife, 2010.

SILVA, Rogério R.; BRANDÃO, Daniel. Os quatro elementos da avaliação. Olho Mágico: Boletim da Rede Unida, Porto Alegre, v. 10, n. 2, p. 52-66, 2003.

SOARES, Greciane et al. Redes de atenção às urgências e emergências: pré-avaliação das unidades de pronto atendimento (UPAs) em uma região metropolitana do Brasil. Revista Brasileira de Saúde Materno-Infantil, Recife, v. 12, n. 4, p. 445-458, 2012.

SOUZA, Luís E. P. F.; VIEIRA-DA-SILVA, Lígia M.; HARTZ, Zulmira M. A. Conferência 
de consenso sobre a imagem objetivo da descentralização da atenção à saúde no Brasil. In: HARTZ, Zulmira M. A.; VIEIRA-DA-SILVA, Lígia M. Avaliação em saúde: dos modelos teóricos à prática na avaliação de programas. Rio de Janeiro: Editora Fiocruz; Salvador: EDUFBA, 2005. p. 65-102.

TAMAKI, Edson M. et al. Metodologia de construção de um painel de indicadores para o monitoramento e a avaliação da gestão do SUS. Ciência \& Saúde Coletiva, Rio de Janeiro, v. 17, n. 4, p. 839-849, 2012.
UCHOA, Alice C. et al. Utilizando técnicas de consenso: potencialidades e limites na avaliação de informações em saúde. In: HARTZ, Zulmira M. A.; FELISBERTO, Eronildo; VIEIRA-DA-SILVA, Lígia M. (orgs.). Meta-avaliação da atenção básica à saúde: teoria e prática. Rio de Janeiro: Editora Fiocruz, 2008. p. 253-275.

Recebido em 03/06/2013

Aprovado em 12/08/2015 